This item was submitted to Loughborough's Research Repository by the author.

Items in Figshare are protected by copyright, with all rights reserved, unless otherwise indicated.

\title{
Toward intersubjective ethics in community-based research
}

\author{
PLEASE CITE THE PUBLISHED VERSION \\ https://doi.org/10.1080/15575330.2020.1777178 \\ PUBLISHER
}

Taylor \& Francis

VERSION

AM (Accepted Manuscript)

PUBLISHER STATEMENT

This is an Accepted Manuscript of an article published by Taylor \& Francis in Community Development on 4 June 2020, available online: http://www.tandfonline.com/10.1080/15575330.2020.1777178.

\section{LICENCE}

CC BY-NC-ND 4.0

\section{REPOSITORY RECORD}

van Zyl, Izak, and Amalia Sabiescu. 2020. "Toward Intersubjective Ethics in Community-based Research". Loughborough University. https://hdl.handle.net/2134/12576515.v1. 


\title{
Toward Intersubjective Ethics in Community-based Research
}

\author{
Izak van Zyl \\ Cape Peninsula University of Technology \\ vanzyliz@cput.ac.za \\ Amalia Sabiescu \\ Loughborough University London \\ a.g.sabiescu@lboro.ac.uk
}

\begin{abstract}
In this paper, we introduce intersubjective ethics as an approach to ethical practice in community-based research. We argue for the need to think of ethics as an evolving process that is inseparable from the research endeavour, and that dwells on relationships and dialogues among researchers and community members. At the core of our approach is 'intersubjectivity' and the related notions of 'critical subjectivity' and 'critical intersubjectivity'; concepts which are central to participatory inquiry but resonate equally with critical theory and constructivism. The paper describes and exemplifies key characteristics of intersubjective ethics and its relation with research. Furthermore, we introduce key elements that can sensitise the researcher-practitioner to the principles of intersubjective ethics and how to put it in practice in community-based research, by cultivating qualities of self-reflexivity and critical (inter)subjectivity.
\end{abstract}

\section{Keywords}

Intersubjective ethics; community development; critical subjectivity, critical intersubjectivity.

This is the accepted version of the article, published version accessible at: https://doi.org/10.1080/15575330.2020.1777178

Cite as: Izak van Zyl \& Amalia Sabiescu (2020): Toward intersubjective ethics in communitybased research, Community Development, DOI: 10.1080/15575330.2020.1777178 


\section{Introduction: Towards a shared ethical paradigm}

"From the vantage point of the colonized, a position from which I write, and choose to privilege, the term 'research' is inextricably linked to European imperialism and colonialism." (Smith, 2013, p. 1)

In this article, we argue for ethics and ethical practice as an emerging, situated, and negotiated enactment when conducting social scientific and empirical research. We locate our argument within the domain of community-based research (CBR) that includes some form of intervention, transformation, or design component. Our stance and the ethical approach we propose resonate particularly with participatory CBR, which also provides a favorable framework for putting it into practice. However, we contend as well that any kind of long-term community-based research should cultivate sensitivity to the ethical issues we tackle in this article. Ethics in these types of endeavors is in many cases both constrained and constraining, delivered and shaped from and within a singular (institutional) paradigm. We notice this tension most acutely when conducting research with minority, indigenous, and vulnerable communities, which may adhere to different paradigms, and which may conceptualize and justify ethical practice in ways not previously anticipated by the researcher-designer-interventionist. In short, we hold that there are unexplored and unresolved tensions and complexities in the ethical engagements between researchpractitioners and participant communities.

The introductory quotation serves to contextualize the intellectual position that we assume and advance in this article. Like Smith (2013), we regard research as a "site of struggle" between the ways of knowing of the West, and the ways of being of the Other. It is within this site that we ground our forthcoming argument, in that the ethical enactment of research is enshrined in hegemonic institutions and decision-making that promote a generic, biomedical model of ethical inquiry (Denzin \& Giardina, 2016). This model is typically administered through institutional review boards (IRBs) or research ethics committees (RECs), which uphold a fixed directive that governs ethical research practice in most if not all institutions of higher learning (Haggerty, 2016). In both contrast and critique, we advance a social science ethics of resistance that departs from monolithic regulations and develops toward intersubjectivity, heterogeneity, and situatedness.

Our argument echoes recent intellectual discussions around ethical research practice (see for example Dalton, 2018; Neufeld et al., 2019; Tomaselli, 2016). Regardless of academic debates and arguments, we and others are still bound by indivisible and slow-moving structures - boards, committees, faculties - that frame our ethical practice on one hand and determine our research outcomes on the other. In our professional academic experience, and in the experiences of others, we rarely observe a "liberated" and situated ethical paradigm, one that is detached from impersonal institutional prescriptions and germane to the social conditions in which we work. As we shall argue, contemporary ethics in academic research is typically systematic and prescriptive, underpinned by a rational paradigm in which justice-based (respect of individual human rights and fairness) and deontological principles (harm avoidance and delegation of responsibilities) are central (Preissle, 2008). Of course, this is to varying degrees and varying outcomes. What underpins this variety, however, is a tendency to enter the field with pre-packaged principles, protocols, and ready-made forms to sign, typically overlooking or ignoring the divergent points of view that may stem from participants.

Against this background, we open the question: What are the considerations and conditions that enable a shared ethical paradigm in community-based research? In addressing this question, we call for the departure from pre-defined, pre-packaged ethics approaches, 
towards approaches that are anchored in process, that are emergent, and that are co-created and shared in a research site. We term this intersubjective ethics, referring to the grounding of ethics approaches in intersubjectivity, shared understandings, and practices. We define intersubjective ethics as the approach to research ethics grounded in a mutually agreed relationship between researchers and communities, underpinned and accompanied by:

- ontological and epistemological assumptions that are shared, made transparent, and acknowledged by each side;

- $\quad$ shared and mutually understood vocabularies; and

- jointly shaped and agreed ethical protocols and any associated tools and forms.

Thus, intersubjective ethics does away with pre-defined procedures and tools, and instead provides the principles and the framework for such instruments to be crafted jointly in the field. The concept of intersubjectivity is central to the approach we propose. As unpacked at length later in the article, intersubjectivity points to the creation of a shared space of relating, communicating, and understanding from which the complex reality of CBR can be navigated by both sides during research. The researcher as active agent can move in this space equipped with critical subjectivity - an awareness of both the roots and the limits of their own socially and culturally shaped stance and understanding, and an openness to the views and beliefs of others, as they contribute together to the shaping of reality.

Our approach resonates with other ethics frameworks, in particular relational ethics, situated ethics, and hermeneutic ethics, as well as ethics approaches in indigenous and participatory research (see Friesen, Kearns, Redman, \& Caplan, 2017). At the same time, it bears some distinctive features that sets it apart from other approaches. A first key distinction regards the ontological and epistemological position assumed, which situates intersubjective ethics in the intellectual scholarship of participatory inquiry, critical theory, and constructivism. Ultimately, we argue that there is a need to reconsider the epistemological grounds upon which one stands when entering the field. This, we maintain, enables CBR ethics to be shared with communities, rather than being unilaterally imposed by research institutions. Otherwise, the risk is always there for an ethics approach to be defined in apparent collaboration, while actually working in the ways of thinking defined by one party. In this regard, we unpack the ontological and epistemological foundations of intersubjective ethics and flesh out the concepts of intersubjectivity and critical intersubjectivity, on which the approach rests.

A second key distinction is the rejection of pre-packaged protocols, and an insistence on emergence, process, and the creation of a space from which protocols and related tools can be defined and produced in the field. We contend that one of the most striking failures of ethics as currently practiced in CBR is to reduce it to tools, forms, and procedures. We argue in this regard that ethics is the process that ensures willing, informed, and potentially beneficial participation in research, a process which is at best facilitated by forms and signatures when these are crafted together with communities during research. This quality of emergence is cultivated throughout the research activity, by means of socialization, joint practice, and a deliberate effort to both make explicit and to understand the other's epistemological position, vocabulary, and cherished values.

Thirdly, intersubjective ethics marks the passage from the intellectual position it assumes to action in the field by focusing on and assigning responsibility to the researcher. Real, systemic change of ethics approaches in CBR is bound to happen very slowly. As we will argue, however, educating aspiring researchers and cultivating qualities of reflexivity and self-reflexivity can compensate by preparing researchers for ethical practice, even within the framework of more rigid institutional structures.

This article brings a threefold contribution to the academic discourse: 
1) It offers a structured assessment of the limits of ethical approaches as often used in CBR, from paradigmatic differences in views and assumptions between research bodies and communities to the pre-packaged approaches, vocabularies, and protocols brought into the field. We will illustrate these issues with vignettes from community-based research in which we have participated ourselves.

2) It introduces intersubjective ethics as a means to resist and transcend these limits.

3) It describes the main principles of intersubjective ethics and proposes ways to enact these principles by focusing on the researcher as an agent of change.

In the sections that follow, we make a case for the need to rethink ethics in CBR, by pointing to the limits of current approaches. In particular, we isolate and discuss three major limits, associated with the failure to acknowledge and account for:

1) paradigmatic differences between researchers and community members at the ontological, epistemological, and axiological level;

2) the intertwinement between ethics and research;

3) the diversity of vocabularies, tools, and protocols for sanctioning research agreements within an ethics approach.

We illustrate these themes with four vignettes from our own research experience with vulnerable communities in Europe and Africa. Having thoroughly argued for the limits of current approaches, we introduce intersubjective ethics and position it in relation to other ethics approaches that challenge the status quo, describing its distinctive features. The final section of this article then puts forth ways to enact these principles in the field, proposing that the researcher can be seen in such endeavors as an agent and catalyst for change. We introduce key elements that can sensitize the researcher-practitioner to the principles of intersubjective ethics, even if (or especially when) they are compelled by ethics committees to go into the field with ready-made forms and protocols. Ultimately, we propose that the researcher and the education of future researchers can compensate at least in part for the reductionist and monolithic approach of ethics committees in (typically Western) universities and research centers. By enhancing researchers' reflexivity and sensitivity to the field through their research training, the road can be paved towards more significant change.

\section{The case for a shared ethical paradigm in community-based research}

The ethical issues posed by research in community settings have been surfaced with poignancy in indigenous research. A common claim is that ethics as often practiced in indigenous community-based research is a form of "constraining ethics," typically predetermined, created from one side (institutional or academic) and not mutually negotiated. This form of ethics lacks input and understanding from the people with whom research is being conducted (Flicker, Travers, Guta, McDonald, \& Meagher, 2007). Such a form of research ethics is paternalistic and potentially colonialist, in the way of subjugating participants by means of fixed and exogenous ideas that they are not given the possibility to understand, negotiate, or simply refuse. It is based on these understandings that indigenous research has taken great leaps to distance itself from its colonialist legacy. Alternative ethics approaches have been advanced, such as Kaupapa Maori research, designed and conducted with and for Maori, and abiding by Maori cultural, epistemological, and ethical principles (see Hudson, Milne, Reynolds, Russell, \& Smith, 2010). Community ethics committees have been formed and protocols drafted in indigenous settings from Canada and the US to Australia and recently, Southern Africa (see EU Trust Project, 2018).

These issues are not however unique to indigenous settings; rather they apply to CBR in many different environments. In this article, we argue that these issues most often boil down to a critical aspect: adopting a sound, mutually respectful ethical approach is a process and not a 
product of pre-defined frameworks and tools. As an ongoing process, it takes time and willingness to engage on multiple sides, as well as relationship building. Ethics is not a "thing" that can be handed over and agreed or signed, not even a protocol to be followed. It is the process that may start from or use such initial guidelines and protocols, bringing multiple sides into a dialogue. In the absence of time, processes, and relations to understand and negotiate one's ethics approach against that of others, implications will arise that are bound to affect not only the relation but also the research itself and its outcomes.

In what follows, we introduce a structured analysis of the limits and potential implications of ethics as currently practiced in CBR, illustrated by examples from CBR projects in which we have taken part, spanning three critical aspects:

1) The first has to do with wide-ranging differences stemming from different paradigms, or ontological and epistemological assumptions endorsed by institutional RECs and communities respectively. As the first vignette introduced below indicates, while academic institutions adhere to an ethics meta-model that respects individual property and decisions, many communities (such as indigenous ones) adhere to collective models of ownership and decision-making. For instance, knowledge may be regarded as a collective rather than an individual asset.

2) The second aspect deals with the intertwinement between ethics and research, and how cultural issues permeate and influence the research endeavor in ways that are difficult if not impossible to anticipate before entering the field. The second vignette provides an example of how cultural values and local customs can be at odds with assumptions regarding ethical choice and behavior endorsed by university ethics committees.

3) The third aspect regards the constraining side of ready-made ethics forms and processes that researchers oftentimes bring with them into the field. The third vignette illustrates how taken-for-granted concepts like "research," "data," and "interview" have rich semantic strata that cannot be quickly grasped if the participant has had no prior experience with research. Furthermore, the entire process can be regarded as tokenistic and overpowering from the side of the research institution, as the participant has no choice and no power to alter the procedures. Their choice is only to adhere or to step back. By agreeing to participate in the research, they do not merely agree to provide information, but implicitly they also agree that the way of treating the information and their rights by the research institution is legitimate. The final vignette exemplifies how the notion that forms and signatures could sanction rights and obligations of individuals is another external framework imposed upon the communities involved in research.

\section{Clashing paradigms}

Ethics paradigms endorsed by university boards and RECs clash with local or indigenous knowledge and ethics systems at the level of meta-ethics, namely the assumptions underlying ethical judgements and choices, framed by certain ontological and epistemological principles (Preissle, 2008, p. 275). For instance, such clashes may encompass assumptions about the nature of knowledge, its preservation, and its ownership. The assumption that knowledge resides in interaction and shared engagement can be at odds with one that it can be written down and maintain its full significance; or, the conviction that knowledge belongs to and can be freely shared by individuals can clash with one that it belongs to the entire community and is thus not an individual asset. The bearing of meta-ethics in field research is shaped by two sets of considerations:

1) the extent to which the principles of meta-ethics affect and guide decisions and conduct, with degrees on a scale between absolutist and relativist positions; 
2) the unit of decision-making, with variations from individual to collective (Preissle, 2008).

Regarding the first consideration, individual communities tend to present context-specific ethical issues. These cannot be addressed by applying generic guidelines and procedures in a top-down manner (Patterson, Jackson, \& Edwards, 2006). Conversely, some researchers propose that certain ethical frameworks may apply broadly to provide some indications of principles to be considered while conducting CBR - an example is participatory research principles such as transparency and respect (Macaulay et al., 1998), or general ethical codes that can be adapted for specific contexts (Flicker et al., 2007). These can take the form of guidelines for conducting research with minority groups, covering aspects around community involvement in research and data ownership (e.g., National Health and Medical Research Council of Australia, 2018).

Regarding the unit of decision-making, individualism and collectivism are two positions to consider. The individualist position concerns assumptions about individual rights and the inviolability of individual property and free will, which are operationalized in procedures such as individual consent forms (Marshall \& Rossman, 2006; Smith, 2013). In different contexts, however, decisions over important matters are the prerogative of the community and therefore embedded in a collective decision-making unit (Preissle, 2008).

A question that opens broader debate is: What happens when RECs/university boards and community-based ethical paradigms clash? The clash can be acknowledged in the beginning stages of a research project if an emergent approach to enacting ethics is taken, allowing it to be shaped in the field; or it can creep into and affect the research process in unforeseen ways. We illustrate this issue below, in a vignette that exemplifies how university RECs and communities may endorse different views on who possesses and has the right to decide on keeping and sharing knowledge, be it the individual or the group, and how these different assumptions engender different understandings around the "legitimate" ethical approaches and tools that can be employed in CBR.

\section{Vignette 1: Who decides? Tenets of individualism and collectivism}

The second author conducted a participatory project with two Roma minority communities in rural Romania (Sabiescu, 2011, 2013). Drafting and negotiating a sound ethical approach was a complex, long-term process. Romani communities are highly hierarchical, where a leader (traditionally called bulibaşă), though unofficial, has wide powers recognized by community members and assumes responsibility over key matters and decisions. The researcher embarked on fieldwork, prepared to meet the ethical requirements of academic research, which embraced principles of no harm and free, prior, and informed consent. In addition, she wanted to conform with the requirements of CBR. Based on initial community visits, she prepared a draft community agreement covering matters of collective concern. Armed with this draft, with annexed copies of the information sheet and individual consent forms, she met the leaders of one of the communities.

The leader and other participants were however baffled by this complex approach: from their stance, once the leader had given their consent, there was no point at all to continue to ask for individual consent forms to be signed. It was simply not necessary. The researcher explained at length the principles underlying the individual consent; why it was important for every person to acknowledge their participation and agree with it; how each step in the agreement was designed to protect the rights and the data of each individual participant. None of these arguments gained ground with the leaders. Rather, the matter was settled and agreed when the researcher simply acknowledged that the consent forms were necessary for her to demonstrate to her university that she had abided by the ethical rules in place. This was sufficient for the 
community leaders to concur with - because they finally recognized the importance of the approach to individual consent and the forms, but as a concession in the frame of an ongoing relationship. Thus, the research was punctuated by an initial, non-binding community agreement as frame of reference, and individual consent forms for every individual participant.

This vignette illustrates how REC and community ethics systems can clash at the paradigmatic, meta-ethics level, in this case with respect to the unit of decision-making, varying from individual to collective. It demonstrates the importance of acknowledging clashes or potential clashes from the outset, but also that even if acknowledged, solving them requires flexibility and openness on both sides, and solutions may be different from those defined before the field research. In this case, solving the clash did not mean adhering to a mutually agreed ethical framework. While both sides were willing to collaborate with and satisfy the requirements of the other side, the rigidity of the institutional framework meant that a real half-way solution to ethics was not feasible. The community leader simply agreed to protocols and forms not because he thought they were useful or would meet his community's requirements, but rather as a sine qua non to move on with the research project. This vignette also shows how institutional rigidity may lead to tokenistic forms of embracing community requirements into negotiated ethical approaches. In contrast, the importance of acknowledging and coming to terms with one's epistemological position, and the recognition that others' may be at odds with one's own, is a key feature of intersubjective ethics, as is explained in greater detail in a later section.

\section{Ethics, culture, and research}

In community-based research, ethics is often treated as a separate aspect or consideration, which can be designed prior to entering the field (see Israel, 2017). As we argue throughout this article, and as demonstrated by the following vignette, ethical issues are interwoven with and carry implications for how research with communities is practiced. This pertains specifically to the fluid and complex interactions between research and normative or moral ethics. When faced with certain cultural-ethical dilemmas, researchers must often re-evaluate their own positions in relation to participants. These dilemmas may come up in research interventions that seek to contribute to social or behavioral change. They may thus consider whether it is ethically acceptable to (intend to) change behavior that is high-risk when that same behavior is culturally sanctioned. The vignette below describes the matter of different, often conflicting, frames of reference when conducting community-based research, and how these impact both the ethics approach adopted and the course of the research itself.

\section{Vignette 2: Cultural scripts}

The first author has been working as an anthropologist-ethnographer with poor local communities in the peri-urban outskirts of the Western Cape of South Africa (see Van Zyl, 2015). The initial research project was formalized on the basis of "actively working with" community organizations and members to address some of their problems in health and wellbeing via collaborative interventions. These problems are multiple and included teenage and unwanted pregnancies, gender-based violence, multidimensional poverty, workplace abuse, alcoholism, and unprotected multiple partnerships. Through design and action research methods, the researcher (as part of a bigger team) set out to meet with stakeholders, learn about the environment, and explore ways through which the respective issues could be tackled, collectively.

As a first step in this project, the researcher engaged a local non-government organization offering community-based health education. The idea behind this engagement was to help the organization address an existing social problem within the local area. One such problem that the organization had long attempted to tackle is disease prevention among Xhosa 
males and females who often engage in unprotected sex, increasing the risk of contracting and spreading sexually transmitted infections. To this end, the organization deploys health workers throughout the community to promote healthy sexual behavior, primarily among the amaXhosa but not excluding Afrikaans and migrant worker communities. The health workers generally adhere to a traditional biomedical model of health promotion, which emphasizes contraception (e.g., by freely distributing condoms), proactive prevention (e.g., by encouraging medical male circumcision), and medical treatment (e.g., by referring at-risk patients to nearby clinics). The researcher spent time in so-called "high-transmission areas" in the community (like the taxi rank) and, together with health workers, approached local members to learn more about their circumstances.

As became apparent in conversations with community members, the biomedical model was implicitly and explicitly rejected on part of many Xhosa males and females, due largely to the religious and cultural beliefs underpinning their behavior. LeClerc-Madlala (2009) terms this as an example of a "cultural script": a widely held value or custom that informs acceptable sexual behavior, often in contrast to biomedical ideas of what it means to be "healthy" and "safe." Many of the local participants regard sex as an entrenched and natural right, especially on part of the males. Furthermore, protected sex (using contraceptives like condoms) and medical male circumcision are two highly contentious matters that are perceived to undermine (rather than encourage) physical wellbeing. Contraception is often regarded as unnatural, "un-cultural," or unreligious, even despite the high risk of contracting HIV and other sexually transmitted infections. Some community members expressed that they would knowingly engage in unprotected sexual activity, even with HIV positive partners, because condoms were not "from God." In addition, young Xhosa males expressed that they would rather undergo the dangerous (often fatal) initiation rite known as "Ulwaluko," through which they "learn to become men," as opposed to being medically circumcised.

The exhibited cultural scripts challenge a conventional biomedical model but also affect the practice of research ethics. Team members in this project were faced with conflicting frames of reference, in which cultural scripts stood in opposition to conventional "healthy" behavior. Moreover, the research team adhered to a dominant Western model from which to develop health interventions. This dominant model is enshrined in a research protocol of bioethics that emphasizes beneficence, nonmaleficence (do no harm), autonomy, and justice (Beauchamp \& Childress, 2012). In the research field, however, team members had to negotiate new and unforeseen complexities in their engagement with local "sexual ecologies" (Preston-Whyte, 1999) that challenge conventional ideas about autonomous research participants and social justice. Indeed, participants admitted to exposing themselves willfully to harm. Team members had to come to terms with such "culturally sanctioned" instances of self-harm to ensure that their interventions would be just and not infringe on the autonomy of research participants.

This vignette, albeit simplified, illustrates the relativism of frames of reference (or paradigms) - ontological, cultural, ethical, and otherwise - that is often overlooked or even subjugated in empirical field research. This points specifically to the inseparability of research and ethics, where ethical practice is not simply about adherence to protocols, but about people rooted in different cultural paradigms trying to make sense of their environment.

\section{Ready-made tools and protocols}

Information sheets and informed consent forms are the standard tools employed by RECs and university boards to ensure that research participants receive proper information about their rights and the implications of their partaking in the research. It is also common that the wording of informed consent forms is established and approved well before the researcher collects actual 
data. In the absence of a prior long-term research relationship with a community, the field researcher would typically meet participants armed already with an information sheet to read, agree upon, and sign. Our experience in these types of activities raises two important issues:

1) Firstly, pre-conceived and -worded protocols, even when efforts are made to render the language accessible and transparent, may remain obscure for research participants.

2) Secondly, even when there is flexibility to change the wording through negotiation, the base issue persists in the very idea that rights and obligations of an individual and an institution can be sanctioned through a set of signatures.

Two vignettes will illustrate these issues.

\section{Vignette 3: Taken for granted vocabularies and their meanings}

One of the authors has conducted research with vulnerable communities in both urban and rural environments. In each research project, ethics procedures were carefully considered, weighing considerations from the university RECs and review boards on the one hand, and community views and needs on the other. The degree of flexibility of the ethics approach, however, would most often be dictated by the nature of the project and the RECs, rather than by community solicitations. For long-term community engagement projects she was involved in, like her doctoral research (2013), the project timeline and approach were flexible enough to give ample time for the consent forms and information sheets to be revised several times by integrating feedback from participants, before being finalized and signed. However, having sufficient time available for shaping ethics approaches on the field was the exception, rather than the rule. In a recent European Union project on access to adult education for vulnerable young people (201619), data collection had fixed dates; moreover, the consent forms and information sheets had been pre-approved by both the university REC and the European Commission. Very significant changes would have required another (lengthy) round of institutional approvals. In practice, with a set time for fieldwork, this meant that the consent form was an almost finished product; the participant's choice was limited to ticking several boxes (e.g., agreeing or refusing to be recorded, or to have their anonymized data archived).

At the beginning of a verbal interview, the principles underlying the consent form were explained, ensuring the participant that this was part of a rigorous process of data capture and archiving, which had at heart the participant's wellbeing and intended to minimize the risk of identity exposure or harm. Most participants continued to sign the form, often with remarks that indicated they valued the trust inspired by the researcher - or the mediator who recruited them for the interview - or they simply regarded it as a necessary condition to move on with the interview. The language had been carefully edited for simplicity and clarity, and there were explanations for terms such as "research" and "data." However, conversations revealed that the conceptual baggage underneath these terms could not be conveyed in the short time put aside for an interview. On several occasions, a lack of understanding generated mistrust in the research project and its underlying aims and uncertainty over what would happen with the information provided. For example, a young woman listened attentively to the description of the ethics procedures. Upon reading the provisions of the consent form, however, she expressed her willingness to take part in the research but did not want to be interviewed. Only after repeated clarifications, it emerged that the woman thought the interview would be broadcast on radio or television. This is what she understood an interview to be, which is legitimate considering that this is the only kind of interview she had heard about. The discussion revealed that the misunderstanding was not merely related to terminology, about two different uses of the word "interview." Rather, more nuanced differences in meaning emerged, as well as issues of value and data use. Firstly, the participant could not understand why an interview that was not being 
broadcast was valuable merely for the information she provided, and that the story she had to tell was meaningful and informative for a complex network of researchers, universities, and other social organizations researching adult education for vulnerable young people. Second, it was difficult to convey how and why this interview was considered "data," and what would happen with it afterwards. Indeed, to understand data use, one would need to understand the fundamentals of research and the research process, from data collection to analysis and interpretation. Also, the fact that an interview is anonymized requires one to understand how interviews are manipulated, transcribed, and analyzed after having attentively eliminated all details that could lead to the identification of participants.

This issue was exacerbated with other participants in the project who were illiterate. Having never engaged with written information, the entire ethics package delivered with the interview was not only obscure, but also intimidating. The conversations revealed that eventually, interviewees had only their trust in the researcher, or the mediator who facilitated participation, to guarantee that it was safe, even potentially valuable and useful to participate in the research. This conclusion is immensely revealing for ethics as practiced in CBR, insofar as it illustrates that despite the great pains taken to ensure willing, informed, and safe participation, as long as this is done via pre-written forms, the ethics approach remains paternalistic, whereas the participant will still resort to trustful relationships to guarantee that it is safe to take part.

The crux of the matter as revealed by this example is thus not only a terminological shortcoming, but the difficulty of communicating very complex processes through words, when one lacks an experiential understanding of the matters explained. The link between conceptual (or propositional) and experiential knowledge (Heron \& Reason, 1997), and the importance of acknowledging gaps between the two, is one of the aspects tackled by intersubjective ethics taken up later in the article.

\section{Vignette 4: Signatures and verbal consent}

In a similar encounter, one of the authors attempted to interview respondents in Grabouw, South Africa, about their experiences of community health initiatives. The research process and method were explained to all participants in the form of a focus group. Yet, while all agreed to be interviewed, most respondents did not want to sign any consent forms. Some did not appear to understand why their signatures were needed when they had already verbally agreed to participate. Others felt that they did not really know what they were signing, and therefore declined to sign in principle. Others yet hesitated, but signed, seemingly to avoid being perceived as obstructive. In that moment, the researcher decided to abolish the signing of the forms and proceeded to interview the participants based on their verbal acknowledgement. This act may have jeopardized the standing of the project with the REC but was necessary in obtaining the trust of the respondents and in making them feel comfortable. By foregoing signatures, the researcher ensured that the fieldwork went ahead as planned, in order not to inconvenience the large group of participants who dedicated their time to the project.

These vignettes indicate that community-based research often abides by rules and protocols that are pre-defined, sanctioned, and imposed from one side. In this way, academic research reduces ethics to protocols that endorse a series of values by imposing them unilaterally. In doing so, the underlying ethical paradigm is taken for granted as a universally accepted and understood one. The examples above indicate that such frameworks are often not understood, ranging from their basic principles (that often remain implicit) to typical protocols and tools such as consent forms.

The fields of community-based research, participatory action research initiatives, and indigenous studies are maturing, and have made important strides in the last few decades 
(Stevenson, 2016; Tomaselli, 2016). But the problem remains: how do we enable a new (or different) perspective on ethics in community-based research, while being aware of the vast constraints on researchers who do try to work within a shared ethics paradigm? We propose that one critical step is to focus on the researcher as key agent, to enhance their sensitivity to issues posed by ethics in the case of community-based research. For this, in the following sections we first define intersubjective ethics as a process evolving alongside research rather than a toolkit or set of procedures and position it against other salient ethics paradigms and approaches. On this basis, in the final section we offer a series of considerations for enacting intersubjective ethics focusing on the central role of the researcher.

\section{Positioning intersubjective ethics Intersubjectivity and critical intersubjectivity}

At the core of our approach is the notion of "intersubjectivity," which is central to participatory inquiry but resonates equally with critical theory and constructivism. In these paradigms, the separation between ontology and epistemology is blurred, insofar as knowing is closely linked to the interaction between the knowing agent and the object of knowledge (Guba \& Lincoln, 1994). In the participatory worldview, knowing and knowledge are of a subjective-objective nature, created in the interaction between the knowing agent and the object of knowledge (Heron \& Reason, 1997). Reality, or the reality that can be known and experienced, can only be uncovered through participation: "To experience anything is to participate in it, and to participate is both to mould and to encounter; hence experiential reality is always subjective-objective" (Heron \& Reason, 1997, p. 278).

The subjective-objective nature of "knowable reality" also implies that there is no possibility to have a direct and final knowledge of all that there is (Heron \& Reason, 1997; Reason \& Bradbury, 2001). The knowing agent shapes reality through their perception while interacting with it. This ontological and epistemological stance has a strong bearing on research and the relation with ethics. Firstly, the notion of intersubjectivity inherent in the negotiation of reality means that the objective distance covered in positivist approaches is not attainable. This is a well-established truth in indigenous research approaches such as in the case of Kaupapa Maori: "To invoke distance in a Maori research project would be to deny that it is a Maori project. It would have different goals, not Maori goals" (Bishop, 2005, p. 119).

Secondly, research is an evolving, transformative process. Participatory inquiry argues that any kind of research is transformative, and there is no such thing as research that merely collects data and leaves no trace. As research involves an act of knowing and any act of knowing is experiential, research will leave its traces whether it acknowledges it or not. Moreover, the traces it will leave cannot always be anticipated: research evolves as process, and so does its transformative potential. This is significant in the case of CBR, as the effects of research can echo in local structures, processes of knowing and understanding, power, and relationships among community members and with researchers. All these aspects have an axiological or ethical dimension to them, which cannot be consummated through pre-defined tools and protocols such as the requirement of written informed consent. This sort of effect is more immediately noticeable in interventionist and participatory research, where a research intervention might for instance benefit a certain group of people, or simply instill among the other members of a community the thinking that it only benefits some of them, potentially creating tension or even conflict (see Sabiescu, 2013; Sabiescu, David, Van Zyl, \& Cantoni, 2014 for an expanded argument on this topic).

Third, knowledge and knowing run deep into the subjective experiencing of the world. Heron and Reason (1997) speak of four forms of knowledge and knowing, experiential, 
presentational, propositional, and practical, which are interconnected and build on each other. Propositional (or conceptual) knowledge works with concepts but can be devoid of meaning if it is not building on the agent's first-hand experience, like in the case of purely verbalizing unfamiliar ethics principles to a community that has not previously been exposed to them. This is significant for ethics approaches, as it implies that mere communication of guidelines and protocols at propositional level, by any party involved in CBR, is grounded unilaterally in that party's experiential understanding of the world. There is no guarantee that the other side will grasp the full implications and the unspoken assumptions of such pre-packaged protocols. Underlying assumptions made by researchers and research participants may be completely at odds, as illustrated in the first vignette about tensions between individual versus collective decisionmaking frames.

How then do we navigate this complex subjective-objective reality in CBR? Heron and Reason (1997) propose the concepts of critical subjectivity and critical intersubjectivity as ways to both scope and gear methodological approaches that are sensitive to these ontologicalepistemological premises. In this article, we extend these notions to frame a reflexive and selfreflexive approach to intersubjective ethics.

Critical subjectivity is a form of awareness of one's subjective position and individual perspective in interpreting the world, coupled with the capacity to manage subjectivity and express it by cultivating a self-reflexive and critical attitude. As per Heron and Reason (1997), it indicates awareness of the possible forms of knowing and the ability to use them in full understanding of the way they are related. In research, this means that the inquirer needs to be aware of the experiential baggage on which any propositional form relies, and therefore the contextual and culturally determined nature of these forms.

Critical intersubjectivity is an awareness of the shared experiential and cultural baggage, and of the larger context which influences our thinking and acting, and at the same time gives the possibility for sharing, exchange, and communication. According to Heron and Reason (1997), critical subjectivity is intricately related to critical intersubjectivity. To be aware and reflexive about one's own unilateral meaning-making and knowing perspective (critical subjectivity) implies that one opens up to others' viewpoints and ideas through dialogue and exchanges (critical intersubjectivity).

In the following section, we extend these notions to characterize intersubjective ethics by singling out the importance of reflexivity and focusing on the agent and the self-reflexive attitude. As we will argue further, the key to instantiating intersubjective ethics is to expand the qualities of the researchers and participants in CBR as self-reflexive agents.

\section{Features of intersubjective ethics}

We propose intersubjective ethics as an ethics approach that rejects pre-packaged ethics tools and guidelines, and instead offers a framework for defining and creating relevant tools and guidelines in or from the field. This frames ethics as a dynamic process, which evolves alongside the field research though dialogue among researchers and community members.

At a meta-ethical level, intersubjective ethics endorses principles akin to indigenous ethics. At this level, both intersubjective and indigenous ethics acknowledge differences between local or indigenous and Western ethical frameworks (e.g., aspects of collective versus individual attribution). The process of socialization is inherent in understanding, negotiating, and endorsing an ethical approach that is embraced by all community members. Most importantly, ethics and research are not separated; they are designed and evolve together. Practical principles for the conduct of research should thus also be negotiated and abided by on all sides, drawing on 
underlying frameworks that may come equally from the researchers' or the community's side (e.g., drawing on established indigenous research frameworks such as Kaupapa Maori).

The focus on relationship building and the value of socialization bring intersubjective ethics into dialogue with relational ethics. Most common in clinical and medical research, relational ethics sees relationships as the pivotal point and the "fulcrum for ethical action" (Pollard, 2015, p. 364). It embraces tenets such as "mutual respect, engagement, embodied knowledge, environment and uncertainty" (Pollard, 2015). The central role granted to relationships dwells on the assumption that human beings, communities, and environments are interconnected, thus ethical principles and action need to be preceded by a firm understanding of how culture and traditions frame our subjective position and the unavoidable unilateral interpretation of the world; this asks then for a critical attitude and consideration of other viewpoints and interpretations (Bergum, 2012; Gadow, 1999).

Like relational ethics, the ethics paradigm associated with participatory community-based research (Flicker et al., 2007) places value on relationships, in the understanding that any truth is materialized in the middle, through, and in the relationships established during research. Participatory approaches acknowledge that ethics understandings, just like ethics protocols and practical action, can (and perhaps should) be co-created in the field. Participatory forms of CBR have attempted and at times succeeded to counter some of these pitfalls through grassroots community involvement. Supporting community involvement is inherent in the very principles endorsed by participatory CBR, going back to the first formulations of action research in the work of Kurt Lewin in the 1940s and even earlier in the community development actions carried out in Austria in 1913 by J. L. Moreno (Hearn, Tacchi, Foth, \& Lennie, 2009). The philosophy of putting research in the service of society endorsed by Lewin was strengthened in time by research in the Global South, which emphasized the participative dimension and produced specific methodologies for grassroots involvement, for instance in the frame of participatory rural appraisal (Chambers, 1994) and the theorization of participatory principles in the work of South American thinkers such as the liberal educator Paulo Freire and Orlando Fals-Borda (Hearn et al., 2009). Participatory research approaches have been applied in manifold fields related to community development, including rural development, information and communication technologies for development, agriculture, and health studies, to name just a few. However, as the literature on the limits of participation amply demonstrates (e.g., Winschiers-Theophilus, Chivuno-Kuria, Kapuire, Bidwell, \& Blake, 2010), solutions employed are often fragmented, involving partial or superficial forms of participation (Sabiescu, David, Van Zyl, \& Cantoni, 2014).

Intersubjective ethics resonates with these approaches in both principle and practical action. The distinctiveness of intersubjective ethics resides in its three qualities. First, intersubjective ethics recognizes that the gap between different understandings or frames of ethics lies deep, at the level of basic ontological, epistemological, and axiological assumptions endorsed by the different parties involved in the research endeavor. These differences cannot be anticipated and catered for by preparing to enter the field with a ready-made ethical package. This remark defines our intellectual position in that before becoming "something" that can be laid out in protocols and represented in a material form, ethics is a process that shadows the research progression closely. This implies that ethics cannot be pre-defined as "a thing" preceding the research - with protocols, consent forms, and obligations to sign. If it ever becomes "a thing," then it should be resulting from a field-anchored process, not preceding the field research. Whenever ethics precedes research and is brought on the field with its array of pre-defined ideas and tools, it becomes a constraining factor or purely a procedural hurdle to resolve. Thus, one of the fundamental distinctive features of our approach is that we do not take ethics to be a framework - no matter how flexible, thoughtful, and amenable to being adapted 
and useful in context that may be. While a framework that guides action can be part of intersubjective ethics, ethics is not the framework itself, but rather a process that permeates research.

This leads to its second quality, a departure from pre-defined, pre-packaged approaches - whether stemming from single-sided or even negotiated encounters - and towards an approach to ethics that is anchored in process, is emergent, and is co-created in a research site. This draws on and expands the notions of critical subjectivity and critical intersubjectivity, which imply that ethics is instantiated, formulated, and given shape at the crossroads among various subjectivities and intersubjective systems (such as socio-cultural systems, or research systems) through shared practices and interaction. Intersubjectivity is the epistemological dimension of emerging in a new, shared, negotiated space. Through appropriate engagement in joint practice, participants make sense, together, of the ethics system that best sustains their joint effort. This implies the need for joint practice, relatedness, and dialogue as the basis for a sound ethical approach to take shape.

Third, the considerations above lend to intersubjective ethics a quality of facilitated emergence. Shared ethics is a process as much as it is the product which can take the form of agreements, protocols, and taboos. Yet, it is important to acknowledge that intersubjective ethics will not just arise from a research situation; it is not naturally emerging. Especially when the participating community is unaware of ethics implications, they may be adamant about or uninterested in adhering to a shared ethics system. This underscores the importance of preparing the ground for shared ethics to emerge. Empirical research, which has some prepared guidance and design - research questions, protocols for data collection, and the like - should typically leave space for new, unexpected dynamics to emerge; so too shared ethics needs a starting point and a grounding. In a sense, shared ethics is one of the research questions of a new CBR project. Just like a regular research question, a process can be put in place to guide the elicitation of knowledge and actions to nurture it through the course of research (see Neufeld et al., 2019 for a discussion on similar concerns and a proposed practical process to elicit local views of community ethics, drawing on work with a heavily researched Canadian community).

We propose that the emergence of intersubjective ethics dwells on a shared space made by the alignment of epistemological assumptions and principles, to avoid empty terms and superficial understandings. This in turns requires socialization and joint practice, rather than purely verbal interaction and transmission of concepts and principles. Thus, the epistemological and the relational dimensions of this process are interconnected, and they rely on the process of research for grounding. By engaging in shared practices and dialogue, it is possible to arrive at joint understandings regarding ethics, the supposed "Other", and the research situation. This pool of joint understandings gives rise to the intersubjective dimension of ethics that we argue for.

\section{Practicing intersubjective ethics}

The discussion thus far has centered around the principles of intersubjective ethics as a response to the predetermined and Western ideological ethics that is practiced by many researchers in the field. Indeed, research with human participants already starts from a position of ethical tension: people are asked to take part in activities or processes that they did not normally request or seek out, and that are not fully (or at all) intended for their benefit (Guillemin \& Gillam, 2004). Community members often do not understand the notion of empirical research, its associated terminologies and methodologies, as is demonstrated in the third and fourth vignettes. We here witness a cultural politics of translation (see Temple \& Young, 2004), through 
which assumptions are created and sustained. Community members may, as a result, harbor certain pre-conceived expectations, which may further complicate the ethical tension.

What is yet unknown and challenging to decipher is how to enact these principles with sensitivity in the field, stepping away from pre-packaged conventions to more responsive and localized approaches. Conversely, there can be no single and uniform means to put intersubjective ethics into practice, given the very dynamic and interconnected nature of such an ethics. There can be no recipe or ready-made guideline:

[T] he issue is that there may be no universal prescribed, orthodox, or agreed upon ethical standards, only universal values (on human rights), general guidelines, and "a set of negotiated practices" that shift from site to site and from cultural group to cultural group (Denzin \& Lincoln, 2008, p.568).

How, rather, do we engage and negotiate the existing constraints of empirical research and institutional ethics protocols? We describe therefore a few considerations that go to the foundations of practicing intersubjective ethics. These may be interpreted differently by different field researchers and may gain different connotations when translated into practical approaches. The central guiding aim is to strive towards a shared ethical paradigm, even if this can never be fully realized.

The foremost consideration is understanding the space (for action and for change). Firstly, this means to know - or attempt to know - the constraints and opportunities presented to the researcher. These include the conditions imposed by institutional ethics committees, often underpinned by "principlism" - the universally accepted values that apply when faced with moral dilemmas, like autonomy, harm avoidance, justice, and beneficence (DeMarco, 2005). It is to know the historical evolution of the way research is handled by such committees - their role in preventing harm, ensuring informed consent, and, meeting certain institutional protocols and standards. More importantly, knowing is to learn about the community participating in research: its history, its socio-cultural make-up, and its politics. Knowing is also to learn about the deep lying roots of a given research and ethics paradigm - with its own principles that may be at odds with the very CBR project that requires ethics approval. Of course, "understanding" is not absolute, objective, and without context. Moreover, it requires considerable personal and social investment, which may in turn necessitate classic ethnographic methods of deep dialogical exchange with others. Whatever means of learning and understanding may be used, the underlying imperative is that an awareness must be created around the space(s) in which research action will take place.

This points to a second important consideration, namely being in the field. Being is about certain presence-bound, reflexive, and sensitive qualities of the researcher. These may include a constant but unobtrusive presence, awareness, empathy, trust, patience, and the ability to - at least temporarily - forgo moral judgements. Being centers around the lived experience of the researcher, an experiential knower as part of a larger social group (central to the anthropological notion of participant observation, for example). The researcher develops and internalizes these qualities over time; they are not merely taught and acquired. Key to being, furthermore, is reflexivity, which means an acknowledgement of microethics: "those ethical dimensions of ordinary, everyday research practice" (Guillemin \& Gillam, 2004, p. 276). This means being attuned to the various (ethically) important moments in research, and their particularities. To be reflexive means, finally, to have the ability to develop ways of addressing and responding to micro-ethical issues as they arise (Guillemin \& Gillam, 2004).

Another means of putting intersubjective ethics into practice is the development of personal social relationships with community members in order to create a hermeneutic 'third space' (Sabiescu, David, Van Zyl, \& Cantoni, 2014). This space resembles a "fusion of horizons" 
(Gadamer, 1975) between the viewpoints of the researcher(s) and the community members. The focus here is on the micro social relations between different people and the creation of knowledge through those relations. This can take the form of a kind of narrative ethics, whereby community voices are elevated with the aim of developing collective narratives between researchers and community partners (Neufeld et al., 2019; Stevenson, 2016). Such an ethics would situate researchers and communities in a "system of relationality not only with one another but also with themselves" (Stevenson, 2016, p. 373). Or, it can also mean that the research project is dismantled and re-negotiated in this third space, so that stakeholders may thus legitimately question the origins, aims, and rationale of a project, its intended benefits, its limitations, and its real-world implications. Such a third space can be created even despite institutional ethical protocols, but this requires time and long-term engagement. Furthermore, it requires interest, patience, and engagement on part of the community.

\section{Concluding thoughts and implications}

Throughout this article, we have highlighted that ethics and research are intertwined and inseparable. We have advanced a perspective on ethics that problematizes the nature and process of research in community contexts. The implication here is that ethics is a lived activity/reality and not a one-off, fleeting set of assumptions and codes of conduct. Much like the broader "research initiative," it is emergent, constant, and relational, not fixed or ahistorical or short-lived. It is also mutual and open to reciprocal change. This argument works to problematize, at an existential level, what community-based research is. Is it a goal-driven, temporary activity, in favor of increasing the outputs and stature of the researcher-practitioner (with some superficial benefit to the "community")? Or is it an immersive, embedded "lived reality" by which new social relationships are forged, and through which (rich) cultural knowledge is generated on all parts?

For all practical purposes, and at the risk of oversimplification, the first type of research is what exists and what has existed for a long time. It is simply not feasible to advocate for truly engaged community-based research given the pressing economic demands of universities and professional life. Even long-trusted anthropological methods of deep ethnographic immersion have succumbed to more business-like, "rapid" and short-term ethnographies (see Jordan, 2016). But idealistic as it may be, if the true purpose of any social-scientific inquiry is to understand, and to learn from others, and to gain new knowledge, then surely that inquiry must be strongly rooted in the spatial-temporal presence(s) of social life? Stated differently: when we do research, we need to recognize that it must be done in an emergent environment/context, with other people, over time. This implies varying power (im)balances, relationships, agendas, behaviors, actions, and interpretations: a cultural-political cacophony of voices and subjectivities. In this article, we have argued that ethics cannot be divorced from this engaged, localized, immersive process of research. It also cannot be separated from the social reality of the participating communities. Rather, ethics resides in the "spaces in between" people and their social environment.

Advancing a perspective of intersubjective and shared ethics does not immediately resolve the many ethical tensions that are inherent to contemporary community-based research. When embracing this perspective, one must consider several aspects, including a meta-ethical view of the research initiative to be undertaken. This may help the researcher to think about different sets of normative ethics and how they would manifest in practice (see McCloskey, 1969). The researcher in addition must consider the "decision-making units" in communities, for example, in cases where collective decision-making may override individual consent (as illustrated in the first vignette). Moreover, the researcher must balance the stringent requirements 
of their ethics review boards with the fluid and unpredictable nuances of the field. Ultimately, the researcher must seek an active engagement with their community partners to be able to negotiate the other's frame of reference, and to develop a new space of thinking, knowledge, and action, with shared assumptions and principles.

\section{References}

Beauchamp, T. L., \& Childress, J. F. (2012). Principles of biomedical ethics (7th ed.). Oxford: Oxford University Press.

Bergum, V. (2012). Relational ethics for nursing. In J. Storch, P. Rodney, \& R. Starzomski (Eds.), Toward a moral horizon: Nursing ethics for leadership and practice (pp. 127-142). Toronto: Pearson Education Canada.

Bishop, R. (2005). Freeing ourselves from neocolonial domination in research. In N. K. Denzin \& Y. S. Lincoln (Eds.), Handbook of qualitative research (3rd ed., pp.109-138). Thousand Oaks: Sage.

Chambers, R. (1994). The origins and practice of participatory rural appraisal. World Development, 22(7), 953-969.

Dalton, D. M. (2018). The ethics of resistance: Tyranny of the absolute. London: Bloomsbury Publishing.

DeMarco, J. P. (2005). Principlism and moral dilemmas: A new principle. Journal of Medical Ethics, 31(2), 101-105.

Denzin, N. K., \& Giardina, M. D. (Eds.). (2016). Ethical futures in qualitative research: Decolonizing the politics of knowledge. London: Routledge.

Denzin, N. K., \& Lincoln, Y. S. (2008). Introduction: Critical methodologies and indigenous inquiry. In N. K. Denzin, Y. S. Lincoln, \& L. Tuhiwai Smith (Eds.), Handbook of critical indigenous methodologies (pp. 1-20). Thousand Oaks, CA: Sage.

EU Trust Project. (2018). Retrieved 24 January 2019. http://trust-project.eu/

Flicker, S., Travers, R., Guta, A., McDonald, S., \& Meagher, A. (2007). Ethical dilemmas in community-based participatory research: Recommendations for institutional review boards. Journal of Urban Health, 84(4), 478-493.

Friesen, P., Kearns, L., Redman, B. K., \& Caplan, A. L. (2017). Extending ethical strides: From tribal IRBs to the Bronx Community Research Review Board. The American Journal of Bioethics, 17(11), W5-W8.

Gadamer, H. G. (1975). Truth and method. New York: Continuum.

Gadow, S. (1999). Relational narrative: The postmodern turn in nursing ethics. Scholarly Inquiry for Nursing Practice, 13(1), 57-70.

Guba, E. G., \& Lincoln, Y. S. (1994). Competing paradigms in qualitative research. In N. K. Denzin \& Y. S. Lincoln (Eds.), Handbook of qualitative research (p. 105-117).

Guillemin, M., \& Gillam, L. (2004). Ethics, reflexivity, and "ethically important moments" in research. Qualitative Inquiry, 10(2), 261-280.

Haggerty, K. (2016). Ethics creep: Governing social science research in the name of ethics. In M. Adorjan \& R. Ricciardelli (Eds.), Engaging with ethics in international criminological research (pp. 29-51). New York: Routledge.

Hearn, G., Tacchi, J., Foth, M., \& Lennie, J. (2009). Action research and new media: Concepts, methods and cases. Cresskill, NJ: Hampton Press, Inc.

Heron, J., \& Reason, P. (1997). A participatory inquiry paradigm. Qualitative Inquiry, 3(3), 274294. 
Hudson, M., Milne, M., Reynolds, P., Russell, K., \& Smith, B. (2010). Te Ara Tika guidelines for Māori research ethics: $A$ framework for researchers and ethics committee members. Auckland: Health Research Council of New Zealand.

Israel, M. (2017). Ethical imperialism? Exporting research ethics to the global South. In R. Iphofen \& M. Tolich (Eds.), The Sage handbook of qualitative research ethics. London: Sage.

Jordan, B. (Ed.). (2016). Advancing ethnography in corporate environments: Challenges and emerging opportunities. New York: Routledge.

LeClerc-Madlala, S. (2009). Cultural scripts for multiple and concurrent partnerships in southern Africa: Why HIV prevention needs anthropology. Sexual Health, 6(2), 103-110.

Macaulay, A. C., Delormier, T., McComber, A. M., Cross, E. J., Potvin, L. P., Paradis, G., \& Desrosiers, S. (1998). Participatory research with native community of Kahnawake creates innovative Code of Research Ethics. Canadian Journal of Public Health. Revue canadienne de santé publique, 89(2), 105-108.

Marshall, C., \& Rossman, G. B. (2006) Designing qualitative research (4th ed.). Thousand Oaks, CA: Sage.

McCloskey, H. J. (1969). Meta-ethics and normative ethics. The Hague: Springer.

National Health and Medical Research Council of Australia (NHMRC). (2018). Ethical conduct in research with Aboriginal and Torres Strait Islander Peoples and communities. Accessed 21 November 2019, https://bit.ly/2QEXYrc

Neufeld, S. D., Chapman, J., Crier, N., Marsh, S., McLeod, J., \& Deane, L. A. (2019). Research 101: A process for developing local guidelines for ethical research in heavily researched communities. Harm Reduction Journal, 16(1), 41.

Patterson, M., Jackson, R., \& Edwards, N. (2006). Ethics in Aboriginal research: Comments on paradigms, process and two worlds. Canadian Journal of Aboriginal Community-based HIVIAIDS Research, 1(1), 47-57.

Pollard, C. (2015). What is the right thing to do: Use of a relational ethic framework to guide clinical decision-making. International Journal of Caring Science, 8(2), 362-368.

Preissle, J. (2008). Ethics. In L. M. Given (Ed.), Encyclopedia of qualitative research methods (pp. 273-277). Thousand Oaks, CA: Sage.

Preston-Whyte, E. (1999). Reproductive health and the condom dilemma: Identifying situational barriers to HIV protection in South Africa. In J. C. Caldwell (Ed.), Resistances to behavioural change to reduce HIVIAIDS infection in predominantly heterosexual epidemics in third world countries (pp. 139-155). Canberra: Health Transition Centre, National Centre for Epidemiology and Population Health, Australian University.

Reason, P., \& Bradbury, H. (Eds.) (2001). Handbook of action research: Participative inquiry and practice. London: Sage.

Sabiescu, A. G. (2011). Context-responsiveness in Community-based Open Content Creation Initiatives. Implications for Evaluation. Proceedings of CIRN 2011 Community Informatics Conference. Prato, Italy, 9-11 Nov. 2011.

Sabiescu, A. G. (2013). Empowering Minority Voices. Ph.D. dissertation, Faculty of Communication Sciences, Università della Svizzera italiana, Switzerland.

Sabiescu, A., David, S., Van Zyl, I. \& Cantoni, L. (2014). Emerging Spaces in Community-based Participatory Design: Reflections from Two Case Studies. In Proceedings of the $13^{\text {th }}$ Participatory Design Conference 2014, 6-10 October 2014, Windhoek, Namibia.

Smith, L. T. (2013). Decolonizing methodologies: Research and indigenous peoples (2nd ed.). London: Zed Books Ltd. 
Stevenson, S. A. (2016). Toward a narrative ethics: Indigenous community-based research, the ethics of narrative, and the limits of conventional bioethics. Qualitative Inquiry, 22(5), 365-376.

Temple, B., \& Young, A. (2004). Qualitative research and translation dilemmas. Qualitative Research, 4(2), 161-178.

Tomaselli, K. (2016). Research ethics in the Kalahari: Issues, contradictions and concerns. Critical Arts, 30(6), 804-822.

Van Zyl, I. (2015). 'Did God give you these condoms?' Locating the role of technology design in addressing health promotion in Grabouw, South Africa. In Bidwell, N.J., \& WinschiersTheophilus, H. (eds.), At the Intersection of Indigenous and Traditional Knowledge and Technology Design. Santa Rosa, California: Informing Science Press, pp. 285-295.

Winschiers-Theophilus, H., Chivuno-Kuria, S., Kapuire, G. K., Bidwell, N. J., \& Blake, E. (2010). Being participated: A community approach. In Proceedings of the 11th Biennial Participatory Design Conference (pp. 1-10). New York: Association for Computing Machinery. 